\title{
O DANO MORAL NO DIREITO DO TRABALHO: Uma Análise a Partir da Ausência de Quitação das Verbas Rescisórias
}

\author{
Alceu Albino von der Osten Neto \\ Bacharel em Direito pela Faculdade de Direito do Brasil \\ (Unibrasil, Curitiba, PR) e especialista em Direito do Tra- \\ balho pelo Centro Universitário de Curitiba (Unicuritiba). \\ E-mail: alceuosten@hotmail.com
}

\section{Marcos Alfonso Spiess}

Bacharel em Filosofia pela Faculdade São Luiz (FSL, Brusque, SC), mestre e doutorando em Antropologia pela Universidade Federal do Paraná (UFPR, Curitiba, PR). E-mail: spiess.spiess@gmail.com

\section{Resumo}

Com 0 advento da Constituição de 1988, as discussões sobre o dano, inclusive no âmbito moral, ganharam proporções que extrapolaram o debate outrora circunscrito ao Direito civil. 0 presente artigo tem por objetivo problematizar a possibilidade de configuração e indenização por danos morais nas hipóteses de rescisão de contrato laboral que cumulam a ausência da quitação de verbas rescisórias. Após uma investigação acerca do conceito de dano moral, discute-se como a Justiça do Trabalho passou a ter competência para julgar indenizações decorrentes das relações laborais. Em seguida, traz-se à discussão jurisprudências produzidas em diferentes tribunais nacionais. Com isso, será possível identificar os principais fundamentos que possibilitaram, ou não, a indenização por danos morais.

\section{Palavras-chave}

Dano moral. Verbas rescisórias. Direito do trabalho.

THE MORAL DAMAGE IN LABOR LAW: AN ANALYSIS FROM THE RESCISSION OF THE LABOR CONTRACT WITHOUT SEVERANCE PACKAGE

\section{Abstract}

With the advent of the 1988 Federal Constitution, the debate about the damage, including in its moral perspective, got up dimensions that reaches beyond the civil law debate. This paper aims discuss the possibility the compensation for moral damages in cases that the rescission of the labor contract happen without the severance package. After an investigation into the concept of moral damages, it discusses how the Labor Court, gradually, starts having jurisdiction to judge cases involving moral damages. Finally, we proceed to the analysis of 
how the concept of moral damage is discussed in recent judged by Brazilian labor courts. With this, it is possible identified the arguments that justify, or not, the compensation for moral damages.

\section{Keywords}

Moral damage. Severance package. Labor law.

\section{Sumário}

1 Introdução. 2 Conceituando 0 dano moral. 30 dano moral no direito do trabalho. $4 \mathrm{~A}$ ausência de verba rescisória e 0 dano moral. 5 Considerações finais. 6 Referências. 


\section{INTRODUÇÃO}

Com o advento da Constituição de 1988, a indenização por danos morais passou a ser assegurada no ordenamento jurídico brasileiro pelo artigo $5^{\circ}$, incisos V e X. Esta garantia ganhou maiores proporçôes com o Código Civil de 2002, que delimitou tanto a responsabilidade civil objetiva quanto a subjetiva (artigos $186 \mathrm{e}$ 187 do CC), ambas intrinsicamente relacionadas ao artigo 927 do mesmo código, o qual prevê que aquele que causar dano a outrem fica obrigado a repará-lo.

Sem desconsiderar o âmbito do direito civil, mas analisando o horizonte no qual se estabelecem as relaçóes contratuais de trabalho, percebe-se que aqui também há um campo propício para ocorrência de danos, sejam eles materiais ou morais. Tais danos podem atingir, em algumas vezes, o empregador, mas, na maioria dos casos, incidem sobre o empregado, parte hipossuficiente da relação laboral.

Sabendo que os danos podem ocorrer em diferentes momentos da relação trabalhista - pré-contratual, durante o exercício do contrato ou mesmo após a execução do contrato -, este trabalho se limita a discutir julgados que analisam os danos morais que ocorrem após a execução do contrato de trabalho, mais especificamente nos casos quando não há a quitação das verbas rescisórias ao empregado. Nestes casos, é a própria ausência do pagamento das verbas rescisórias que passa a ser arguida como causa do dano moral.

Considerando a alteração ensejada pela Emenda Constitucional no 45, a qual estabeleceu competência à Justiça do Trabalho para processar e julgar as açôes de indenização por dano moral decorrentes das relaçóes de trabalho, tem-se que a discussão sobre a ocorrência ou não do dano, quando não há quitação das verbas rescisórias, ainda é deveras controversa. Conforme será discutido no item quatro deste artigo, as jurisprudências sobre esse assunto são díspares e, mesmo partindo de casos semelhantes, colocam em tela conceitos e interpretaçôes distintas.

Pretende-se, assim, mapear as principais tendências tomadas nos casos que envolvem a indenização pelos danos morais, principalmente quanto ao embasamento teórico oferecido pelos magistrados. Nesse sentido, a primeira parte deste trabalho busca oferecer o suporte teórico sobre o dano no Direito e o dano moral especificamente. Em um segundo momento, expóem-se algumas observaçôes sobre a questão da competência jurídica para julgar o dano moral pela Justiça trabalhista, 
possibilitando compreender melhor os posicionamentos jurisprudenciais acerca do tema. Por fim, após a discussão estritamente teórica, serão debatidos alguns casos que trazem à tona a discussão da ocorrência, ou não, do dano moral nas relaçóes trabalhistas e que incidem após a rescisão do contrato. $\mathrm{O}$ objetivo na utilização destes julgados como pilar central do trabalho é ressaltar quais os argumentos que fundamentam as decisôes que caracterizam ou não o dano, demonstrando as principais tendências e também os principais entraves nesta área do direito.

\section{CONCEITUANDO 0 DANO MORAL}

Antes de se analisar o dano moral nos casos julgados pela Justiça do Trabalho, torna-se necessário conceituá-lo, uma vez que se trata de um instituto inserto em uma esfera mais ampla do Direito positivo.

De modo geral, o dano moral pode ser definido "como toda e qualquer lesão aos valores magnânimos, juridicamente tutelados, de uma determinada pessoa, que lhe cause prejuízos de ordem imaterial e, em princípio, sem conteúdo econômico" (Bastos, 2007, p. 88). Esta breve definição pode ser lapidada e analisada, basicamente, sob duas perspectivas: (i) excludente ou negativa e (ii) enquanto dor ou alteração do estado anímico.

Na primeira perspectiva, o dano moral é definido em contraposição aos danos materiais, ou seja, basicamente é dano moral tudo aquilo que causa ou se traduz em prejuízo, mas desde que este não esteja submetido à ordem econômica. Neste sentido, afirma Francisco Pontes de Miranda (2000, p. 30): "Dano Patrimonial é o dano que atinge o patrimônio do ofendido; dano não patrimonial é o que, só atingindo o devedor como ser humano, não lhe atinge o patrimônio”.

Corroborando com este entendimento, afirma o doutrinador italiano De Cupis (1975, p. 122):

O dano não patrimonial não pode ser definido se não em contraposição ao dano patrimonial. Dano não patrimonial, em consonância com o valor negativo de sua expressão literal, é todo dano privado que não pode compreender-se no dano patrimonial, por ter por objeto um interesse náo patrimonial, ou seja, que guarda relação com um bem não patrimonial. 
Como será possível perceber adiante, apesar de ser amplamente utilizada para fundamentação das jurisprudências, inclusive no direito do trabalho, observa-se que esta definiçáo negativa do dano moral é claudicante. Ao se contrapor ao dano patrimonial, tal perspectiva em nada define o conteúdo do dano moral e sua possibilidade de aferição.

Diversamente, há uma segunda perspectiva na qual se define o dano moral: enquanto dor moral ou alteraçáo do estado anímico. Este posicionamento se torna mais interessante, pois busca definir o próprio conteúdo do dano moral. Segundo o teórico argentino Jorge Alsina (1993, p. 97), o dano moral pode ser entendido "como a lesão aos sentimentos que determina dor ou sofrimentos físicos, inquietação espiritual, ou agravo às afeiçóes legítimas e, em geral, a toda classe de padecimentos insuscetíveis de apreciação pecuniária” (tradução nossa).

No mesmo viés, o professor Carlos Alberto Bittar (1994, p. 31) afirma que tais danos "se traduzem em turbaçóes de ânimo, em reaçôes desagradáveis, desconfortáveis ou constrangedoras, ou outras desse nível, produzidas na esfera do lesado". Observa-se que, diferentemente da definição negativa, há nessas conceituaçóes uma tentativa de definir o conteúdo do dano moral, circunscrevendo-o às dimensōes da dor ou da alteração do estado anímico.

É preciso reconhecer, no entanto, que:

Tais estados psicológicos, [...], constituem nấo o dano em si, mas sua consequência ou repercussão. Confunde-se o dano com o resultado por ele provocado. Dano moral e dor (física ou moral) são vistos como um só fenômeno. Mas o dano (fato logicamente antecedente) não deve ser confundido com a impressão que ele causa na mente ou na alma da vítima (fato logicamente subsequente) (Andrade, 2003, p. 5).

Esta distinção entre dano e dor, entre causa e efeito, torna-se interessante para nossa discussão na medida em que possibilita perceber que muitas das indenizaçóes por danos morais requeridas no âmbito da justiça do trabalho se fundamentam nos efeitos e náo nas causas. Em outros termos, especificamente quando da ausência da quitação das verbas rescisórias, a dor ou a lesão que são alegadas não são propriamente o dano per se, mas sim consequências do dano causado pelo empregador. 
Nos casos adiante analisados, percebe-se que "As dores, angústias, afliçóes, humilhaçóes e padecimentos que atingem a vítima de um evento danoso não constituem mais do que a consequência ou repercussão do dano (seja ele moral ou material)" (Andrade, 2003, p. 6). Noutras palavras, a ausência de quitação das verbas rescisórias e todas as consequências daí decorrentes são, geralmente, danos ligados diretamente ao patrimônio do empregado. É apenas em um segundo momento que estes danos patrimoniais se tornam capazes de repercutir no estado psicológico empregado, e então possibilitariam configurar o denominado dano moral.

De toda forma, as definiçốes aqui elencadas provocam um deslocamento da problematização do dano, passando-se a assegurar não somente a manutenção da ordem e dos direitos ao que se refere aos bens materiais e com objetivos econômicos, mas, agora, é a própria pessoa humana e todos os direitos decorrentes da sua personalidade que passam ao centro das preocupações e discussóes jurídicas. De outro modo,

(...) a ninguém se recusa o direito à vida, à honra, à dignidade, a tudo isso enfim, que sem possuir valor de troca da economia política, nem por isso deixa de constituir em bem valioso para a humanidade inteira. Sáo Direitos que decorrem da própria personalidade humana. São emanaçóes diretas do eu de cada qual, verdadeiros imperativos categóricos da existência humana (Süssekind; Maranhão; Vianna, 2000, p. 632).

Esta concepção do dano moral - consequência decorrente de uma lesão material ou imaterial, que provoca alteraçóes na ordem psicológica da vítima, no seu estado de ânimo, provocando-lhe dores, angústias ou afliçóes - ganhou proporções consideráveis nas demandas trabalhistas. Conforme demonstrarão as jurisprudências a seguir analisadas, é de se observar desde imediato que com este deslocamento conceitual quando, independentemente do dano ser material ou imaterial, passa-se a centralizar a discussáo acerca da pessoa humana e seus direitos de personalidade.

\section{O DANO MORAL NO DIREITO DO TRABALHO}

Antes de se analisar propriamente os julgados, é mister uma breve descrição da relação entre Justiça do Trabalho e dano moral. Com isto, busca-se perceber quais as concepçóes que influenciaram na atribuição de competência à Justiça do Trabalho para decidir sobre os danos morais envolvendo a relação empregador-empregado. 
Se por um lado a Constituição de 1988 é pacífica sobre o dever de se ver compensado quem sofre moralmente, direito este que foi ratificado pelo Código Civil de 2002, por outro, a possibilidade de indenizaçáo trouxe no bojo da discussão muitas controvérsias acerca da competência de quem julgaria referidas açôes, principalmente nos casos que envolvem relaçôes trabalhistas.

Se hoje as discussôes quanto à competência estão pacificadas, é de se reconhecer que o percurso histórico para a delimitação da competência não foi nada pacífico. Observa-se que em 1943, quando da Consolidação das Leis do Trabalho, sequer cogitava-se a possibilidade de indenização por danos materiais, vez que era expressamente excluída a responsabilidade civil do empregador. ${ }^{1}$

Após duas décadas,

$\mathrm{Na}$ Assembléia Constituinte de 1946, o projeto original, além de incluir a Justiça do Trabalho entre os órgãos do Poder Judiciário, atribuía-lhe a competência para julgar os dissídios relativos aos acidentes do trabalho, por se tratar de típica controvérsia decorrente da relação de trabalho. No entanto, foi apresentada a Emenda no 2.662, para excluir a competência das questôes acidentárias da Justiça do Trabalho, para atender aos interesses das companhias seguradoras privadas que temiam a benevolência dos órgáos da Justiça trabalhista em favor dos acidentados (Oliveira, 2005, p. 150).

Tal ressalva, que conservou a competência à Justiça comum nos julgamentos de responsabilidade civil, ainda que decorrente das relaçóes de trabalho, foi mantida tanto pela Constituição de 1967 quanto pela EC de 1969, não obstante as discussóes e posicionamentos contrários que já vinham sendo feitos e que haviam culminado, em 1963, na ediçấo de súmula de no 229 pelo STF, a qual afirmava: "a indenização acidentária não exclui a do direito comum, em caso de dolo ou culpa grave do empregador".

O quadro interpretativo da responsabilidade civil do empregador pelos danos causados aos empregados ganhou novos horizontes somente após a promulgação da Constituição de 1988. Reitera-se aqui que foi também a partir da Carta

${ }^{1}$ Conforme artigo 12 do Decreto nº 24.637 de 1934: "A indenização estatuída pela presente lei exonera o empregador de pagar à vítima, pelo mesmo acidente, qualquer outra indenizaçáo de direito comum". 
Magna que a responsabilidade passou a abarcar não somente os danos materiais, mas também os extrapatrimoniais, o que fez intensificar ainda mais as discussóes acerca da competência nos casos de responsabilidade civil por danos causados na esfera do trabalho.

Durante inúmeras décadas, foi contestada a competência da Justiça do Trabalho para julgar determinados casos que eram atribuídos às funçóes da Justiça comum. Se nos casos acidentários, por exemplo,

a conclusão inarredável é que, após a Constituição da República de 1988, os litígios referentes às indenizaçóes por danos materiais e/ou danos morais postuladas pelo acidentado em face do empregador, provenientes de acidente do trabalho, devem ser apreciados pela Justiça do Trabalho (Oliveira, 2005, p. 155).

Havia, de outro lado, o seguinte questionamento: Nos casos envolvendo danos morais, a quem compete tais julgamentos? Novamente aqui emergiam as divergências. De modo geral, nos primeiros anos deste século tanto o STJ quanto o STF entendiam que competia ao Direito comum amparar a solução dos conflitos indenizatórios, ainda que em casos trabalhistas. É o que pode se aferir do seguinte julgado exarado em 2003, pelo STF:

Competência: Justiça comum. Ação de indenização fundada em acidente de trabalho, ainda quando movida contra o empregador. 1. É da jurisprudência do STF que, em geral, compete à Justiça do Trabalho conhecer de ação indenizatória por danos decorrentes da relação de emprego, não importando deva a controvérsia ser dirimida à luz do Direito comum e não do Direito do Trabalho. 2. Da regra geral são de excluir-se, porém, por força do art. 109, I, da Constituição, as açôes fundadas em acidente de trabalho, sejam as movidas contra a autarquia seguradora, sejam as propostas contra o empregador. STF, 1a T., RE 349.160/ BA, Rel. Min. Sepúlveda Pertence, DJ 19.03.2003.

Em uma perspectiva diversa, o TST atribuía a si a competência de julgar as demandas por danos (materiais, mas também morais) decorrentes da relaçáo de trabalho. Neste sentido, corrobora a Orientação de no 327 da SBDI-I do TST, 
que afirma: "Dano moral. Competência da Justiça do Trabalho. Nos termos do art. 114 da CF/1988, a Justiça do Trabalho é competente para dirimir controvérsias referentes à indenização por dano moral, quando decorrente da relação de trabalho".

No intuito de sanar este embate que já perpassava os tribunais superiores, promulgou-se, em meio a tantas discussóes, a Emenda Constitucional no 45, que, alterando a redação do artigo 114, passou a assegurar que "Compete à Justiça do Trabalho processar e julgar: [...] VI - as açóes de indenização por dano moral e patrimonial, decorrentes da relação de trabalho".

Ressalta-se que o referido inciso não faz nenhuma alusão ao fato específico do dano moral ou material decorrer exclusivamente de acidente de trabalho; ao contrário, ao excluir a espécie e ampliando a concepçáo para o gênero, torna-se competência material da Justiça do Trabalho a solução das lides que requerem indenizaçóes pelos danos causados pelos atos ilícitos dos empregadores aos seus empregados.

Se, por um lado, no entanto, a EC 45 pacificou as controvérsias acerca da competência, agora o problema passou a ser de outra ordem, insurgindo-se novo questionamento: Como configurar e julgar o dano moral decorrente das relaçôes de trabalho?

\section{A AUSÊNCIA DE VERBA RESCISÓRIA E 0 DANO MORAL}

Se a partir da EC 45 não restam mais dúvidas quanto à competência para processar e julgar os casos que envolvem dano moral nas relaçóes de trabalho, por outro, ao atribuir a competência à Justiça especializada, controvérsias começaram a aparecer dentro dos próprios Tribunais do Trabalho, debatendo-se sobre quando e como julgar os danos morais trabalhistas.

Partindo do caso da ausência de quitação das verbas rescisórias, percebe-se que há contradiçôes na caracterização ou não do dano moral, possibilitando inferir, desde logo que, se quanto à competência material o assunto é pacífico, o mesmo não se pode afirmar quanto aos critérios de resolução dos conflitos em questão. 
Partindo de uma análise qualitativa da jurisprudência sobre o assunto, tem-se que são, de modo geral, três os argumentos utilizados para que não haja a caracterização do dano moral quando ausente a quitação das verbas rescisórias, quais sejam: (i) o dano é entendido como exclusivamente patrimonial; (ii) os transtornos psicológicos como mero dissabores do cotidiano, não existindo provas suficientes que ensejem o dano moral; e, (iii) a existência de outras regras jurídicas para aplicação nesses casos.

$\mathrm{Na}$ primeira perspectiva, argumentam os relatores que o dano quando inexistente a quitação das verbas rescisórias, é de ordem estritamente patrimonial, não devendo, pois, se exigir a indenizaçáo por dano moral. Assim, por exemplo, julgou o TRT-PR:

TRT-PR-20-10-2009 I. INTERVALO INTRAJORNADA. SUPRESSÃO PARCIAL. PAGAMENTO APENAS DO PERÍODO FALTANTE PARA SE COMPLETAR O INTERVALO MÍNIMO LEGAL - [...].

\section{DANOS MORAIS. NÃO PAGAMENTO DE VERBAS RESCISÓRIAS}

- Não é devida indenização por dano moral pelo inadimplemento das verbas rescisórias. Por mais que tal situação cause transtornos à vida pessoal de qualquer trabalhador, o dano causado é meramente patrimonial, e não moral (TRT-PR01571-2009-513-09-00-6-ACO-35618-2009 - 1ª Turma. Relator: Edmilson Antonio de Lima - grifamos).

No mesmo sentido, foi o entendimento da $9^{\circ}$ Turma do TRT da $1^{\text {a }}$ Região:

INDENIZAÇÁO POR DANOS MORAIS. O inadimplemento das verbas resilitórias no momento oportuno não enseja, por si só, o pagamento de indenização por danos morais. Recurso a que se dá parcial provimento (TRT-RJ 00485002820085010014, 9a Turma. Relatora: Claudia de Souza Gomes Freire, data da publicação 4/2/2011).

Segue acompanhado pela segunda turma do mesmo Tribunal:

DANO MORAL. CONFIGURAÇÃO. VERBAS RESILITÓRIAS. NÃO-CABIMENTO. O dano moral caracteriza-se pela lesão ocasionada em decorrência de excesso ou abuso de poder, pelo tratamento humilhante dispensado 
ao empregado, violador da integridade moral deste. O inadimplemento de verbas resilitórias, por si só, não é capaz de ensejar a indenização por danos morais (TRT-Rj 01343007220075010074, 2a Turma. Relator: Valmir de Araujo Carvalho, data de julgamento 29-6-2010).

Além desse entendimento, de que a não quitação é apenas um dano patrimonial, há o entendimento de que a ocorrência causa, tão somente, "meros dissabores do cotidiano", não atingindo a personalidade, a imagem ou a honra do empregado. Este argumento, geralmente, vem acompanhado da análise de que não se restou evidenciado com provas suficientes de que o ato (ainda que ilícito) do empregador tenha causado algum dano que pudesse ser caracterizado como dano moral para o empregado.

Caso exemplar é o entendimento do 3a Turma do TRT da 9a Região. Neste, o relator pautou o náo provimento ao pedido compensatório por danos morais por entender que, além de ser dano puramente material, faltaram documentos nos autos que fundamentassem a alegação ao prejuízo moral, conforme se lê:

DANO MORAL. ATRASO/AUSÊNCIA DE PAGAMENTO DE VERBAS DEVIDAS. INEXISTÊNCIA DE PROVA ACERCA DE INADIMPLÊNCIA DE OBRIGAÇÓES PESSOAIS. Embora o atraso no pagamento de verbas salariais, a ausência de pagamento das verbas rescisórias quando da rescisão contratual e o recolhimento a menor do FGTS, via de regra, causem preocupação e incerteza ao empregado, não pode ser taxada como lesiva a sua honra ou boa fama, de modo a sujeitar o empregador ao pagamento da indenização outra que não a legalmente prevista nesse caso, de cunho material. Não há, nos autos, documentos que comprovassem que, efetivamente, dos atos da reclamada tenha decorrido inadimplência de obrigaçóes pessoais, de modo a importar em lesão à sua honra e à boa fama (incisos V e X do art. 5 da Constituição Federal). Recurso ordinário da autora ao qual se nega provimento (TRT-PR-01497-2011-02109-00-6-ACO-55906-2012. 3a Turma. Relator: Archimedes Castro Campos Júnior, data de julgamento 30/11/2012).

Ressalta-se que de acordo com este último julgado, o entendimento é de que não há responsabilidade quando não se tem a prova do dano. Criticando esta concepção, Maria Celina Bodin de Moraes (2003, p. 159 - grifamos) assevera que: 
depois de restar superada a máxima segundo a qual não há responsabilidade sem culpa, tendo-se encontrado na teoria do risco um novo e diverso fundamento da responsabilidade, desmentido se vê hoje, também, o axioma segundo o qual não haveria responsabilidade sem a prova do dano, substituída que foi a comprovação antes exigida pela presunção hominis de que a lesão a qualquer dos aspectos que compóem a dignidade humana gera dano moral.

Por fim, conforme supracitado, um terceiro argumento utilizado para não gerar o direito à indenização pelos danos morais é de que a própria legislação trabalhista possui outros meios de reparação aos danos causados pela ausência do pagamento das verbas devidas. A lógica que perpassa este argumento é que não cabe a possibilidade de o empregador ser penalizado duplamente.

Nesses casos, geralmente figura como fundamento o $\$ 8^{\circ}$ do artigo 477 da CLT, conforme afirmou julgado do TRT da 4a Região:

DANOS MORAIS. ATRASO NO PAGAMENTO DAS VERBAS RESCISÓRIAS. O dano pelo atraso no pagamento de parcela rescisória enseja a aplicação da multa prevista no $\int 8^{\circ}$ do artigo 477 da CLT e não indenização por danos morais. (TRT-RS 0000532-55.2011.5.04.0291, Relator: Marcelo Gonçalves de Oliveira, julgado em 30/5/2012 - grifamos).

Ratificando e complementado este argumento, transcreve-se julgado do TRT de São Paulo:

EMENTA - FALTA DE PAGAMENTO DE VERBAS RECSISÓRIAS - AUSENCIA DE DANOS MORAIS.

O não pagamento de verbas rescisórias, exceto dolo provado, não dá ensejo à indenização por danos morais porquanto a legislação trabalhista contém medidas punitivas e reparadoras, como juros de mora, multas dos artigos 467 e 477 da CLT e, no âmbito processual, há possibilidade de tutela antecipada. Se for entendido que inadimplementos de toda natureza causam danos morais, a cadeia de reparaçóes pode não ter fim. Recurso do empregador provido para excluir da condenação a indenização por danos morais (TRT-SP 01654.2007.055.02.00-2, julgado em 7 de fevereiro de 2011 - grifamos). 
Poder-se-ia trazer, aqui, inúmeras jurisprudências negando a concessão de se ver compensado por danos morais o empregado que, após operada a rescisão contratual de trabalho, não teve suas verbas rescisórias quitadas. Diferentemente, porém, de uma análise quantitativa, a perspectiva analítica qualitativa se torna mais producente para se perceber os argumentos que fundamentam tais decisóes. Conforme pode se perceber, resta evidenciado que, para se negar o pedido indenizatório por danos morais, os julgadores o configuram eminentemente como um dano patrimonial.

Alguns até cogitam a possibilidade de haver dano moral, mas argumentam que, não restando provado nos autos o dano moral, o mesmo não pode ser indenizado. Ademais, ressaltam que a própria CLT possui dispositivos específicos para tanto, visando a punir o empregador quando o mesmo náo adimplir com a quitação integral das verbas rescisórias cabíveis ao empregado.

Em outra perspectiva e em detrimento das análises realizadas pelos Tribunais supracitados, há o entendimento de que a ausência de quitação das veras em comento e que dão ensejo à indenizaçáo por danos morais.

De modo geral, o argumento é de que ao praticar o ato ilícito demitindo o empregado sem a quitação das verbas que lhe são devidas, os empregadores causam àqueles danos a sua personalidade, honra, imagem e provocam dores e alteraçóes psíquicas, justificando a indenização pelos danos morais, sem detrimento de todos os outros reparos materiais que ficam a cargo do empregador.

Neste sentido, fundamentou a $4^{\mathrm{a}}$ Turma de 2a Regiáo:

\begin{abstract}
ATRASO NO PAGAMENTO DAS VERBAS RESCISÓRIAS - DANO MORAL E MATERIAL - CABIMENTO. A ausência de pagamento das verbas rescisórias, do fornecimento da guia para levantamento do seguro-desemprego ou do recolhimento dos depósitos do FGTS gera dano moral ao empregado, porque esses fatos causaram instabilidade financeira, causando sofrimento ao obreiro que não pode mais contar com o resultado da venda de sua força de trabalho. Recurso ordinário da reclamante a que se dá provimento (TRT-SP 028200-59.2008.5.02.0065, $4^{\mathrm{a}}$ Turma, julgado em 7/12/2010 - grifamos).
\end{abstract}


Semelhantemente, e dando provimento ao pedido de indenização, tanto moral quanto material, um julgado do TRT da $1^{\text {a }}$ Regiâo entendeu que é perfeitamente cabível a cumulação de ambos os pedidos. Doutro modo, em detrimento dos argumentos levantados pelos que negam provimento ao dano moral, o julgado transcrito a seguir torna perfeitamente cabível a indenização compensatória por dano moral cumulada com o ressarcimento pelos danos materiais.

\section{DANO MORAL. DESCUMPRIMENTO DE OBRIGAÇÃO CONTRATU-} AL. POSSIBILIDADE. Admitindo a doutrina e jurisprudência no âmbito das relaçóes civis a possibilidade de cumulação de dano material e dano moral por fato comum, com muito mais razão e maior intensidade há de se admiti-la nas relaçôes contratuais de trabalho. $\mathrm{O}$ inadimplemento injustificado da satisfação dos créditos resilitórios, impedindo a manutenção pelo trabalhador de suas necessidades vitais e de sua família, se constitui, por si só, em agravo aos direitos da personalidade. $\mathrm{O}$ digo, especialmente, fundado nas garantias constitucionais, porque fundada a República, dentre outros valores, na dignidade da pessoa humana e do trabalho. E por certo, subtrai-se a dignidade do trabalhador se lhe retiram, por inteiro, os meios de prover suas necessidades básicas. Não é difícil imaginar o sofrimento de quem, tendo perdido o emprego, fica abruptamente à mercê da solidariedade da família ou sofre a degradaçáo da fome e impedido de solver os compromissos assumidos é taxado de mau pagador. Não podemos, por mera abstração, d.v., afirmar que para o homem médio isso é mero dissabor, aborrecimento do cotidiano. É algo que atinge psique do indivíduo, o diminui perante a sociedade, causa-lhe, enfim, constrangimento e sofrimento. No caso específico do reclamante, tais consequências têm fatores agravantes, porque dispensado em 22 de julho, recebeu apenas $\mathrm{R} \$ 119,00$, em razáo das contrataçóes ilícitas efetuadas pela $1^{\mathrm{a}}$ Reclamada e teve que sobreviver com este valor até outubro de 2008, quando recebeu o salário de seu emprego seguinte. Recurso parcialmente provido para acrescer à condenação a indenizaçáo por danos morais, embora em valor menor que o almejado (TRT-RJ - RTOrd 0120600-04.2008.5.01.0071 -6a Turma Rio de Janeiro, 13 de Dezembro de 2010 - grifamos).

Ressalta-se que nesse julgado foram atacados todos os argumentos daqueles que não concedem a indenização pelos danos morais. Primeiro, porque entendem que pelo ato ilícito e injustificado de não quitar as verbas rescisórias, o empregador provoca mais do que prejuízo material ao empregado. Segundo, afirmam que mais 
do que meros dissabores, o prejuízo de ordem moral se fundamenta nas lesóes causadas à personalidade humana, ferindo direitos fundamentais garantidos constitucionalmente, como moradia, saúde e imagem. Por fim, além de ressarcir o dano material, demonstram ser cabível a indenizaçáo pelo dano moral, inclusive como forma de penalizar o empregador a fim de inibir a possibilidade de reincidência por parte do mesmo.

Este último argumento, de punir diretamente o empregador, também fica evidente no entendimento posto pela $10^{\mathrm{a}}$ Turma, também da $1^{\mathrm{a}}$ Regiáo, conforme se verifica neste aresto:

\footnotetext{
RECURSO ORDINÁRIO. DANOS MORAIS. DISPENSA SEM PAGAMENTO DAS VERBAS RESILITÓRIAS. O empregado que é dispensado sem justa causa e sem receber as verbas do distrato está sujeito a sérios problemas financeiros, pondo em risco sua reputação e até sua vida familiar. Por esse motivo, a conduta da reclamada enseja indenização por danos morais - até porque a penalidade tem um viés pedagógico, desestimulando a ré de reiterar sua conduta (TRT-1 a Região - Recurso Ordinário, Relator Flavio Ernesto Rodrigues Silva, julgado em 6/2/2012 - grifamos).
}

Conforme se pode observar dos casos aqui expostos, são latentes as contradiçóes que fundamentam os julgamentos de casos em que há ausência da quitação das verbas rescisórias. Se após a EC 45 a discussão sobre a competência restou pacificada, certamente os entraves atuais são acerca de quais os parâmetros devem ser utilizados para julgar casos de dano moral originários das relaçôes trabalhistas.

Observa-se que todas as jurisprudências aqui trazidas sáo entendimentos firmados nos últimos anos, o que revela que a discussão sobre como e em quais casos configurar o dano moral é, além de controversa, atual. Dessa forma, sem a presunção de responder quais os critérios ou as possibilidades que permitem a caracterização ou não do dano moral, tornou-se perceptível que há certa regularidade nos argumentos tanto a favor quanto contra a indenização por danos morais nas causas em que se fazem ausentes a quitação das verbas rescisórias. 
Conforme anteriormente analisado, para negar a indenização nesses casos, os julgadores geralmente entendem que (i) o dano é exclusivamente patrimonial; (ii) os transtornos psicológicos como mero dissabores do cotidiano, náo existindo provas suficientes que ensejem o dano moral; e, (iii) a existência de outras regras jurídicas para aplicação nesses casos impede a indenização por danos morais.

Diferentemente, os julgados que possibilitam a configuração do dano moral quando da ausência da quitação das verbas rescisórias, além de perceber na indenização uma forma de punir o empregador, ressaltam que a indenização por danos morais tem o condão de compensar as ofensas que atingiram à pessoa humana, sua dignidade, honra e personalidade.

Em última instância, no âmbito teórico foi possível perceber um deslocamento do conceito de dano moral, o qual passa a ser náo apenas oposto ao dano patrimonial, mas coloca no centro do debate a dignidade da pessoa humana. No plano prático dos julgamentos, a discussão entre o que é dano patrimonial e o que fere a dignidade humana é que direciona os julgados.

\section{CONSIDERAÇÕES FINAIS}

Este trabalho buscou analisar os danos morais que surgem no âmbito das relaçóes de trabalho após a execução do contrato de trabalho, quando a rescisão do contrato não é acompanhada das verbas devidas aos trabalhadores.

A partir da Emenda à Constituição Federal de no 45, a qual alterou a redação do artigo 114, houve a pacificação da discussão acerca das competências para se processar e julgar tais casos. Como visto, porém, inúmeros problemas entraram em pauta para os Tribunais do Trabalho, principalmente quanto à ocorrência ou não do dano moral.

Neste sentido, apontando a direção mais frutífera quanto à análise de tais casos, buscou-se analisar o dano moral náo na sua perspectiva negativa, tampouco enquanto alteração do estado de ânimo ou psicológico da vítima. Optou-se, assim, por ressaltar a centralidade que a dignidade da pessoa humana ganha nas discussóes quanto à ocorrência ou não do dano moral em relaçóes trabalhistas. 
Analisando qualitativamente diferentes jurisprudências, tem-se que, enquanto alguns percebem as verbas rescisórias eminentemente como uma questão patrimonial, há, de outro lado, aqueles que percebem que ao bem material são conferidos valores e necessidades que abarcam questóes e direitos básicos da própria existência humana, como a moradia, a saúde e a alimentação.

Dessa forma, assim como há um deslocamento teórico no próprio conceito de dano, tem-se que os julgados aqui analisados circulam por essas diferentes posiçóes teóricas e, a partir daí, acabam definindo pela possibilidade ou pela impossibilidade da indenização por danos morais em casos de ausência do pagamento das verbas rescisórias. As práticas dos tribunais, evidenciadas pelas posiçóes contraditórias supraexpostas, demonstram que a discussão teórica, ainda não pacificada, possui sua relevância nos casos aqui analisados.

Conforme demonstrado, se há de um lado diversos entendimentos quanto à impossibilidade de configurar e indenizar moralmente em casos de ausência de quitaçáo das verbas rescisórias, tratando estas como um dano eminentemente material, há, por outro, inúmeros posicionamentos que, analisando a centralidade da dignidade da pessoa humana, possibilitam a indenizaçáo por danos morais, posto que alegam que é a própria dignidade, honra e estado psicológico que devem ser discutidos e considerados nesses casos.

\section{REFERÊNCIAS}

ANDRADE, André Gustavo C. A evolução do conceito de dano moral. In: Revista da Ajuris, Porto Alegre, n. 92, 2003.

ALSINA, Jorge Bustamante. Teoria general de la responsabilidad civil. 7. ed. Buenos Aires: Abeledo-Perrot. 1993.

BASTOS, Guilherme Augusto Caputo. Danos morais: o conceito, a banalização e a indenização. In: Revista TST, Brasília, v. 73, n. 2, abr./jun. 2007.

BITTAR, Carlos Alberto. Reparação civil por danos morais. In: Revista dos Tribunais. São Paulo, 1994.

DE CUPIS, Adriano. El daño: teoria general de la responsabilidad civil. Barcelona: Bosch Casa Editorial, 1975. 
MIRANDA, Francisco C. Pontes de. Tratado de direito privado. Campinas: Bookseller, 2000. Tomo XXVI.

MORAES, Maria Celina Bodin de. Danos à pessoa humana: uma leitura civil-constitucional dos danos morais. Rio de Janeiro: Renovar, 2003.

OLIVEIRA, Sebastião Geraldo de. A competência para julgar as indenizaçóes por acidente do trabalho após a EC 45/04. In: Revista TST, Brasília, vol. 71, n. 2, maio/ago. 2005.

SÜSSEKIND, Arnaldo; MARANHÃO, Délio; VIANNA, Segadas. Instituiçôes de Direito do trabalho. São Paulo: LTr, 2000. Vol. 1.

Recebido em: 25/9/2015?????

Aceito em: 3/5/2016?????? 